\title{
Structural Electrochemistry from Freestanding Polypyrrole Films: Full Hydrogen Inhibition from Aqueous Solutions
}

\author{
Toribio F. Otero,* Jose G. Martinez, Masaki Fuchiwaki, and Laura Valero
}

Free-standing polypyrrole films, being the metal-polymer contact located several millimeters outside the electrolyte, give stationary closed coulovoltammetric (charge/potential) loop responses to consecutive potential sweeps from $-2.50 \mathrm{~V}$ to $0.65 \mathrm{~V}$ in aqueous solutions. The continuous and closed charge evolution corroborates the presence of reversible film reactions (electroactivity), together high electronic and ionic conductivities in the full potential range. The closed charge loop demonstrates that the irreversible hydrogen evolution is fully inhibited from aqueous solutions of different salts up to $-2.5 \mathrm{~V}$ vs $\mathrm{Ag} / \mathrm{AgCl}$. The morphology of the closed charge loops shows abrupt slope changes corresponding to the four basic components of the structural electrochemistry for a 3D electroactive gel: reduction-shrinking, reduction-compaction, oxidation-relaxation, and oxidation-swelling. Freestanding films of conducting polymers behave as 3D gel electrodes (reactors) at the chain level, where reversible electrochemical reactions drive structural conformational and macroscopic (volume variation) changes. Very slow hydrogen evolution is revealed by coulovoltammetric responses at more cathodic potentials than $-1.1 \mathrm{~V}$ from strong acid solutions, or in neutral salts self-supported blend films of polypyrrole with large organic acids. Conducting polymers overcome graphite, mercury, lead, diamond, or carbon electrodes as hydrogen inhibitors, and can compete with them for some electro-analytical and electrochemical applications in aqueous solutions.

in conducting polymers..$^{[1,2]}$ The electrochemically stimulated conformational relaxation (ESCR) model provides a good description and quantification of the chemically induced structural changes. ${ }^{[3-13]}$ Compacted films have been used to improve metal corrosion protection. ${ }^{[14,15]}$ The use of different packed conformations as initial states for the study of the film oxidation kinetics drives different kinetic coefficients, activation energies, or reaction orders: the kinetic magnitudes include structural information and the chemical kinetics become structural chemical kinetics. ${ }^{[16]}$

The slow reduction-compaction process was demonstrated to go on until cathodic potential limits higher than $-1.5 \mathrm{~V}$ were reached. Nevertheless, at more cathodic potential limits than $-1.1 \mathrm{~V}$, the reduction-compaction overlaps an irreversible reaction attributed to water electrolysis, with hydrogen release, at the polymer/ metal interface. ${ }^{[1]}$ Here, the coulovoltammetric experiments will be repeated in different electrolytes by using free-standing polypyrrole films with the metal contact located outside the electrolyte, trying

\section{Introduction}

Coulovoltammetric responses allow a good graphical separation of the electrochemically induced structural changes

\author{
Prof. T. F. Otero, J. G. Martinez, M. Fuchiwaki, L. Valero \\ Centre for Electrochemistry \\ and Intelligent Materials (CEMI) \\ Universidad Politécnica de Cartagena \\ Aulario II, Paseo Alfonso XIII, E-30203 \\ Cartagena (Murcia), Spain \\ E-mail: toribio.fotero@upct.es \\ Dr. M. Fuchiwaki \\ Kyushu Institute of Technology \\ Department of Mechanical Information Science \\ and Technology, 680-4 Kawazu \\ lizuka (Fukuoka), 820-8502, Japan \\ Dr. L. Valero \\ Electronics department \\ Engineering school \\ Universidad Autónoma del Estado de México \\ Toluca, E-50130, Mexico
}

DOI: 10.1002/adfm.201302469 to prove if, as expected from the hypothesis, this irreversible reaction disappears by elimination of the back metal inside the solution. More cathodic potential limits than $-1.5 \mathrm{~V}$ will be explored in order to follow the reduction-compaction process.

Using the theoretical equations from the ESCR model to quantify charges, energies, and the potential ranges for each structural process becomes a quite specialized task. ${ }^{[3-13]}$ Coulovoltammetric responses from conducting polymers (CPs) coating metal electrodes ${ }^{[1]}$ become easier graphical tools (useful for non-specialists) to separate and quantify the different structural components, and here we try to extend this methodology to free-standing films as working electrodes.

By contrast, with the ESCR model, the conducting-insulator transition model ${ }^{[17-38]}$ claims that any conducting polymer becomes a fully reduced insulator film after the reduction maximum. There the model states that all the counterions are expelled from the film and the positive charges eliminated from the chains. The subsequent oxidation during the next anodic potential sweep must be initiated at the metal/polymer interface: only from those chains (insulator) in direct contact with the metal the electrons can be extracted by oxidation. In that case, the use of free-standing films with a metal contact 
located outside the solution must give, after the first reduction sweep, flat voltammetric responses to consecutive potential cycles due to both the insulating nature of the reduced film and the absence of a polymer/ metal contact inside the solution. We will try to explore here those aspects.

Moreover, the conducting-insulator transition model states that the electroactivity of the film must reduce to zero after the reduction maximum, meanwhile the ESCR model states that the film closes its structure after the maximum still under a partial oxidized state, going on at more cathodic potentials to a slow reduction-compaction process, consuming charge, and expelling ions. Here, we will try to clarify those discrepancies by quantifying the charges consumed in the different potential ranges.

From every basic monomer, seven dif-

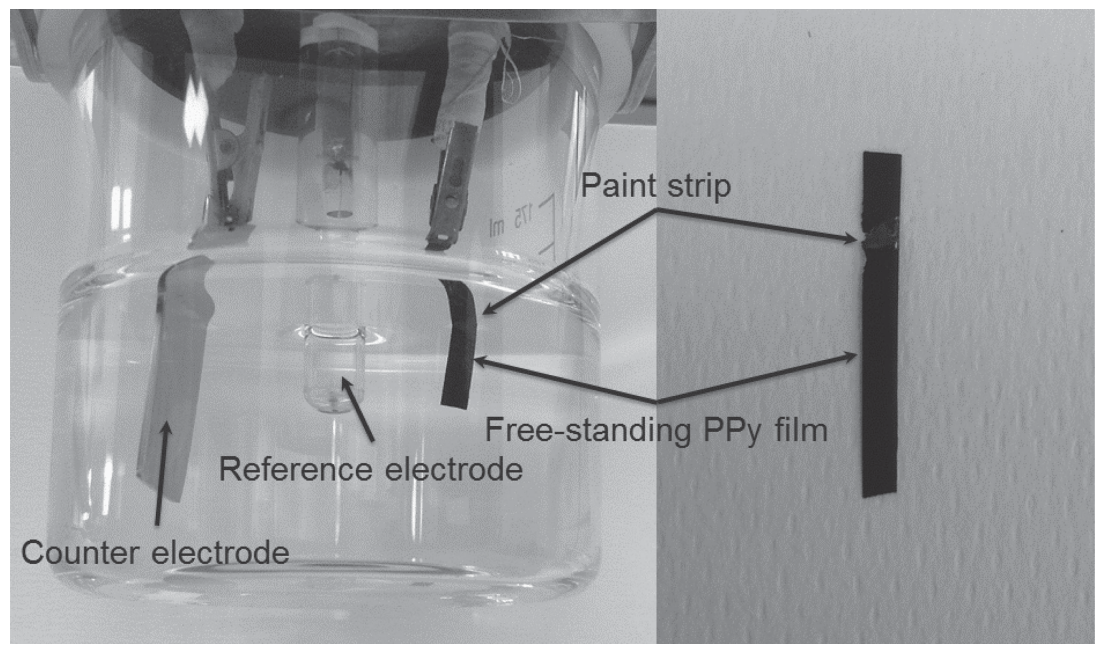

Figure 1. Experimental electrochemical cell. Detail of the self-standing polypyrrole film used as working electrode. ferent families of conducting polymeric materials can be obtained. ${ }^{[39,40]}$ The voltammetric and coulovoltammetric responses could change with the chemical nature of the free-standing films: here we will explore the influence of different counterions by using different electrolytes, different proton concentrations, or films of polypyrrole blend with organic acids.

\section{Results}

\subsection{Free-Standing Polypyrrole Electrodes}

Freestanding reduced polypyrrole (PPy) films were used as electrodes in order to explore their voltammetric behaviour in aqueous electrolytes for different cathodic potential limits. We try to elucidate if, by elimination of the back metal, the irreversible cathodic reaction observed from PPy/metal electrodes in aqueous solution at more cathodic potentials than $-1.1 \mathrm{~V}$ disappears. ${ }^{[1]}$

\subsubsection{Influence of the Cathodic Potential Limit}

The contact between polypyrrole films (of $2 \mathrm{~cm} \mathrm{x} 0.3 \mathrm{~cm}$ and $23 \mu \mathrm{m}$ thick) and the metal clamp was kept $1 \mathrm{~cm}$ above the electrolyte meniscus. From the clamp contact to the electrolyte, both sides of the dry and reduced film were coated with a non-conducting lacquer strip in order to fill any film pore, thus hindering any electrolyte contact (by capillarity through the film pores) with the metal clamp. The length of the film inside the de-aerated electrolyte, $0.1 \mathrm{M} \mathrm{LiClO}_{4}$ aqueous solution, was $1 \mathrm{~cm}$ with $0.44 \mathrm{mg}$ being the immersed polypyrrole mass (Figure 1). The free-standing electrode film was subjected to consecutive potential sweeps in order to get a steady state voltammetric response by erasing any structural material memory ${ }^{[20,41-48]}$ at $1 \mathrm{mV} \mathrm{s}^{-1}$, up to different cathodic potential limits. After two consecutive potential sweeps the attained steady state voltammograms and coulovoltammograms, obtained by its integration, are shown in Figure 2a-d.

Closed steady state coulovoltammetric loops were obtained from consecutive potential sweeps in de-aerated aqueous solutions, whatever the cathodic potential limit, up to $-2.50 \mathrm{~V}$ (Figure $2 \mathrm{~d}$ ). Oxidation reactions produce a positive increment of charge. Reduction reactions give a negative increment of charge. Oxidation charges equal reduction charges: only reversible film reactions take place in the studied potential range. Oxidation and reduction film reactions occur at any potential in the full potential range, as deduced from the continuous variation of the charge at any coulovoltammetric point. The slow film reduction-compaction with negative charge evolution is present from the closing potential until the cathodic potential limit $(-2.5 \mathrm{~V}$, Figure $2 \mathrm{~d})$, and goes on during the beginning of the anodic potential sweep up to the coulovoltammetric minimum, $-0.5 \mathrm{~V}$ (Figure $2 \mathrm{~d}$ ). This large range of reduction reactions in a potential range of $2 \mathrm{~V}$ at the beginning of the anodic potential sweep eliminates any possible interpretation of the reduction-compaction as a capacitive charge. A shorter reaction inertia is also observed at the beginning of the cathodic potential sweep, where the polymer oxidation goes on up to the coulovoltammetric maximum.

No irreversible reaction giving open parts of the coulovoltammetric response was detected. Irreversible hydrogen evolution present at more cathodic potentials than $-1.10 \mathrm{~V}$ from polypyrrole films coating Pt electrodes ${ }^{[1]}$ disappears when the supporting metal contact is eliminated from inside the aqueous solution.

The nature of this irreversible reaction (the hydrogen evolution from water electrolysis) also is corroborated by the large potential windows attained by voltammetric results using metal electrodes coated with films of CPs in dry organic solvents, such as propylene carbonate ${ }^{[11]}$ or acetonitrile. ${ }^{[5]}$ Other self-supported CPs, like polypyrrole/DBSA ${ }^{[49]}$ or PEDOT, ${ }^{[50]}$ also present a broad voltammetric potential window in different solutions.

We can therefore corroborate that the irreversible reduction observed at more cathodic potentials than $-1.1 \mathrm{~V}$ from polypyrrole coating platinum electrodes corresponds to hydrogen evolution from water taking place at the Pt/polymer interface. 


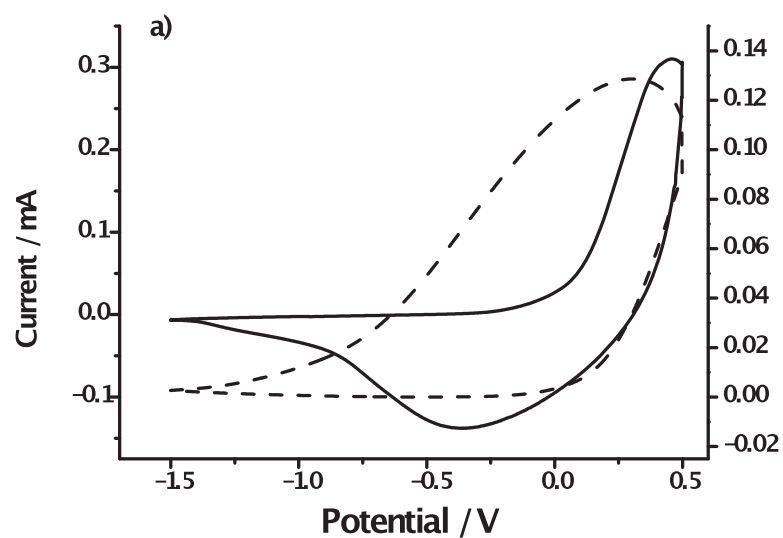

c)

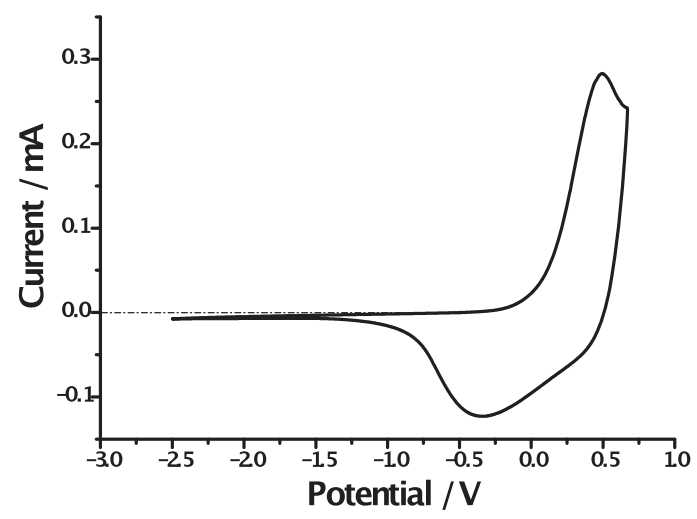

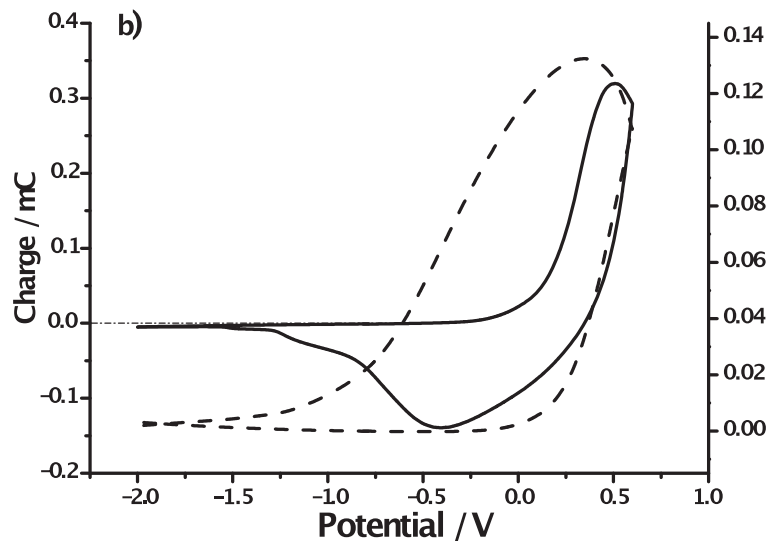

d)

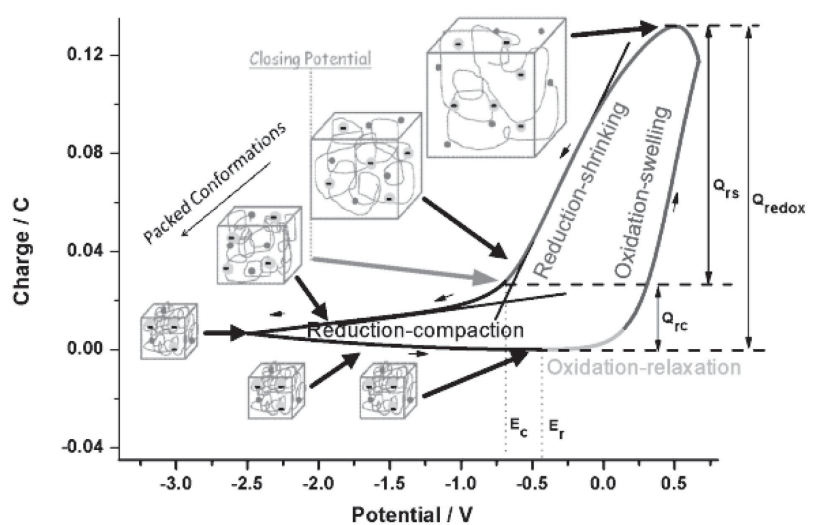

Figure 2. Voltammograms and coulovoltammograms obtained for a free standing polypyrrole film in $0.1 \mathrm{M} \mathrm{LiClO}_{4}$ aqueous solution at $1 \mathrm{mV} \mathrm{s}{ }^{-1}$ from: a) $-1.50 \mathrm{~V}$ to $0.50 \mathrm{~V}$; b) $-2.00 \mathrm{~V}$ to $0.60 \mathrm{~V}$; c) voltammogram from $-2.50 \mathrm{~V}$ to $0.70 \mathrm{~V}$; d) coulovoltammogram obtained by integration of the data in (c). The mass of the polymeric film was $0.44 \mathrm{mg}$.

Freestanding films of conducting polymers expand the potential window of the film redox processes in aqueous solution up to more cathodic potentials than $-2.50 \mathrm{~V}$, with hydrogen evolution being fully inhibited, overcoming $\mathrm{Hg}$ or $\mathrm{Pb}$ electrodes. Conducting polymers behave as stronger hydrogen inhibitors than other carbon-based materials like doped diamond $(-1.25 \mathrm{~V}$ vs NHE), ${ }^{[51,52]}$ graphite $\left(1.3 \mathrm{~V}\right.$ vs. $\left.\mathrm{Li} / \mathrm{Li}^{+}\right),{ }^{\left[{ }^{[3]}\right.}$ or carbon nanotubes $\left(-1 \mathrm{~V}\right.$ vs Ag/AgCl). ${ }^{[54]}$

Figure 1 also evidences that, after deep reduction by potential sweeping up to $-2.5 \mathrm{~V}$, the reduced free-standing film re-oxidizes every time on the consecutive anodic potential sweep, allowing the flow of high anodic currents. The polymer reduction, with charge consumption and flow of cathodic currents, goes on after the cathodic potential limit up to the coulovoltammetric minimum, and then the oxidation/relaxation and swelling starts. Those results contradict both the insulating and the non-reactive nature of the reduced films of CPs after the voltammetric reduction maximum, and the need for a metal/polymer contact inside the solution in order to initiate the re-oxidation of the polymer insulator there during the subsequent anodic sweep, as claimed by the percolation model.

\subsubsection{Structural Coulovoltammograms}

Figure $2 \mathrm{~d}$ presents the coulovoltammetric response of the film. The slope at any point indicates the reaction rate variation (oxidation or reduction) per unit of potential change during the potential sweep: $d Q / d E=F m\left(d\left[A^{-}\right] / d E\right)$, where $Q$ is the charge at the considered point of the coulovoltammogram, $\left[\mathrm{A}^{-}\right]=\mathrm{Q} /$ Fm is the specific concentration of counterions (per mass unit, $\mathrm{m}$, of reduced material involved in the reaction) in the material, and F is the Faraday's constant. Any abrupt change of the slope $(\mathrm{dQ} / \mathrm{dE})$ indicates a similar abrupt change of the reaction rate $\left(\mathrm{d}\left[\mathrm{A}^{-}\right] / \mathrm{dE}\right.$, the variation of the specific concentration of counterions in the film per unit of potential shift), which will be attributed to each of the film structural changes.

The closed coulovoltammetric loop allows the separation, with quantification of the involved charges, of every reduction/oxidation-induced structural process: reduction-shrinking, reduction-compaction, oxidation-relaxation, and oxidation/ swelling (Figure 2d). ${ }^{[1]}$

The intersection point $\mathrm{E}_{\mathrm{c}}$ corresponds to the closing potential. The coulovoltammetric minimum defines the oxidationrelaxation potential, $\mathrm{E}_{\mathrm{r}}$ : the anodic overpotential is high enough 
Table 1. Charges, specific charges, and characteristic potentials obtained from the coulovoltammetric results: $Q_{\text {redox, }}$ total oxidation or reduction reversible charge; $\mathrm{Q}_{\mathrm{rc}}$ reduction/packing charge; $\left(100 \times \mathrm{Q}_{\mathrm{rc}} / \mathrm{Q}_{\mathrm{redox}}\right)$ percentage of charge consumed by conformational packing; mass of the polymeric film immersed in solution during redox reactions; ( $Q_{\text {redox }} /$ mass) specific redox charge; $\left(Q_{r c} /\right.$ mass) specific charge for reduction-compaction; $E_{c}$ closing potential, and; $\mathrm{E}_{\mathrm{r}}$ oxidation-relaxation potential. The self-supported polypyrrole film was subjected to consecutive potential sweeps in $0.1 \mathrm{M}$ $\mathrm{LiClO}_{4}$ aqueous solution at $1 \mathrm{mV} \mathrm{s}^{-1}$ between the indicated cathodic potential limits and $0.7 \mathrm{~V}$.

\begin{tabular}{|c|c|c|c|c|c|c|c|c|}
\hline $\begin{array}{l}\text { Cathodic potential } \\
\text { limit }[\mathrm{V}]\end{array}$ & $\begin{array}{l}\text { Qredox } \\
{[\mathrm{mC}]}\end{array}$ & $\begin{array}{c}Q_{\mathrm{rc}} \\
{[\mathrm{mC}]}\end{array}$ & $\begin{array}{c}\mathrm{Q}_{\mathrm{rc}} / \mathrm{Q}_{\text {redox }} \\
{[\%]}\end{array}$ & $\begin{array}{l}\text { mass } \\
{[\mathrm{mg}]}\end{array}$ & $\begin{array}{c}\mathrm{Q}_{\text {redox }} / \text { mass } \\
{\left[\mathrm{C} \mathrm{g}^{-1}\right]}\end{array}$ & $\begin{array}{c}\mathrm{Q}_{\mathrm{rc}} / \text { mass } \\
{\left[\mathrm{C} \mathrm{g}^{-1}\right]}\end{array}$ & $\begin{array}{l}E_{c} \\
{[V]}\end{array}$ & $\begin{array}{c}E_{r} \\
{[V]}\end{array}$ \\
\hline-1.50 & 0.129 & 0.00717 & 5.56 & 0.4319 & 0.299 & 0.0166 & -0.77 & -0.504 \\
\hline-2.00 & 0.134 & 0.01050 & 7.84 & 0.4130 & 0.324 & 0.0254 & -0.80 & -0.498 \\
\hline-2.50 & 0.132 & 0.01967 & 14.90 & 0.4386 & 0.301 & 0.0448 & -0.70 & -0.485 \\
\hline
\end{tabular}

to initiate the film oxidation by conformational relaxation of the packed structure.

The charge involved from the maximum to the minimum, $\mathrm{Q}_{\text {redox }}$ (Figure 2d), is the charge required for the reversible oxidation/reduction of the film; $\mathrm{Q}_{\mathrm{rc}}$ is the charge consumed to reduce and compact (conformational packing) the film in the potential range from the closing potential to the coulovoltammetric minimum; $\mathrm{Q}_{\mathrm{rs}}=\mathrm{Q}_{\mathrm{redox}}-\mathrm{Q}_{\mathrm{rc}}$ is the charge consumed to reduce and shrink the film. The obtained results for those charges and the specific charges (per unit of polymer mass) from the studied cathodic potential limits are given in Table 1. The percentage of the film redox charge involving the film reduction-compaction at the cathodic potential after the reduction maximum increases with the cathodic potential limit up to $15 \%$ of the full redox charge loop. Getting a fully reduced film looks to be a difficult task when using thick films due to the progressive conformational compaction when the reduction advances hinder the expulsion of counterions from inside the film.

From the voltammetric and coulovoltammetric responses, we can conclude that, at the closing potential, $\mathrm{E}_{\mathrm{c}}$, the film keeps over $15 \%$ of the positive charges present on chains in the fully oxidized film (coulovoltammetric maximum) and, consequently, over $15 \%$ of the balancing counterions. This conclusion is in good agreement with the high $\operatorname{spin}^{[17,55,56]}$ and charged state ${ }^{[57]}$ content detected in reduced films of conducting polymers by electron paramagnetic resonance (EPR) or Raman spectroscopy. Beyond the closing potential, both electronic and ionic film conductivities must be high enough to allow the electrochemical reduction to go beyond $-2.50 \mathrm{~V}$. Most of the available analytical methodologies allow the detection of such high ionic concentrations in the film. The high concentration of positive charges should give high electronic conductivities, allowing different reactions to occur at high cathodic potentials using, as an electrode, the self-supported polymer film. All those aspects, of great scientific and technological interest, will require deeper study in a subsequent paper.

\subsection{Influence of the Polymer/Counterion Material}

The chemical nature of the polypyrrole/anion material changes with the anion exchanged from the electrolyte. It could be expected that different voltammetric responses, and different hydrogen inhibition capabilities, could be obtained after several cyclic voltammograms in different aqueous electrolytes. Figure 3 shows the steady state voltammetric and coulovoltammetric results from aqueous solutions of the same concentration $(0.1 \mathrm{M})$ of different salts $\left(\mathrm{NaCl}, \mathrm{LiNO}_{3}, \mathrm{LiCF}_{3} \mathrm{SO}_{3}\right.$, and $\left.\mathrm{LiF}\right)$, from the same cathodic potential limit of $-2.5 \mathrm{~V}$ and cycled at $3 \mathrm{mV} \mathrm{s}^{-1}$. Closed coulovoltammetric responses are obtained every time, showing the same structural parts described above for Figure 2d, but this time in different potential ranges as they correspond to different materials. Hydrogen evolution is always inhibited.

In addition, strong packing effects are observed inside the same potential range in $\mathrm{NaCl}, \mathrm{LiCF}_{3} \mathrm{SO}_{3}$, and $\mathrm{LiF}$ : the beginning of the polymer oxidation/relaxation is shifted towards more anodic potentials than those observed in $\mathrm{LiNO}_{3}$. As a consequence, the end of the anodic voltammograms and the beginning of the cathodic one show a loop characteristic of nucleation/relaxation processes: the current at the beginning of the cathodic potential sweep is higher (the oxidation is faster) than during the preceding anodic potential sweep. After reductioncompaction, the ESCR model states that the oxidation is initiated by nucleation-relaxation of the conformational packing, as deduced from chronoamperometric results, and this was visualized from electrochromic films of different conducting polymers. ${ }^{[58]}$

\subsection{The Proton's Influence}

In order to check the hydrogen-inhibiting ability, the polypyrrole films were checked in strong acid solutions. Figure 4 shows the voltammetric and coulovoltammetric responses from the polypyrrole film in $0.1 \mathrm{M} \mathrm{HClO}_{4}$ aqueous solutions for two different potential limits, -1.5 and $-2.5 \mathrm{~V}$. No hydrogen gas evolution can be deduced from the voltammetric responses, but the presence of a slow irreversible hydrogen evolution is revealed from the coulovoltammetric response in Figure $4 \mathrm{~b}$ at more cathodic potentials than $-1.1 \mathrm{~V}$ by the irreversible reduction charge of the open part outside the loop. The response presents, in addition, the same structural regions as described above for the different electrolytes. The proton's discharge with hydrogen evolution is so slow, even from such a high proton concentration, that it doesn't produce any increase of the cathodic current during the potential sweeps. For comparison, a more significant discharge can be observed from polypyrrolecoated platinum electrodes with a similar surface area and film 

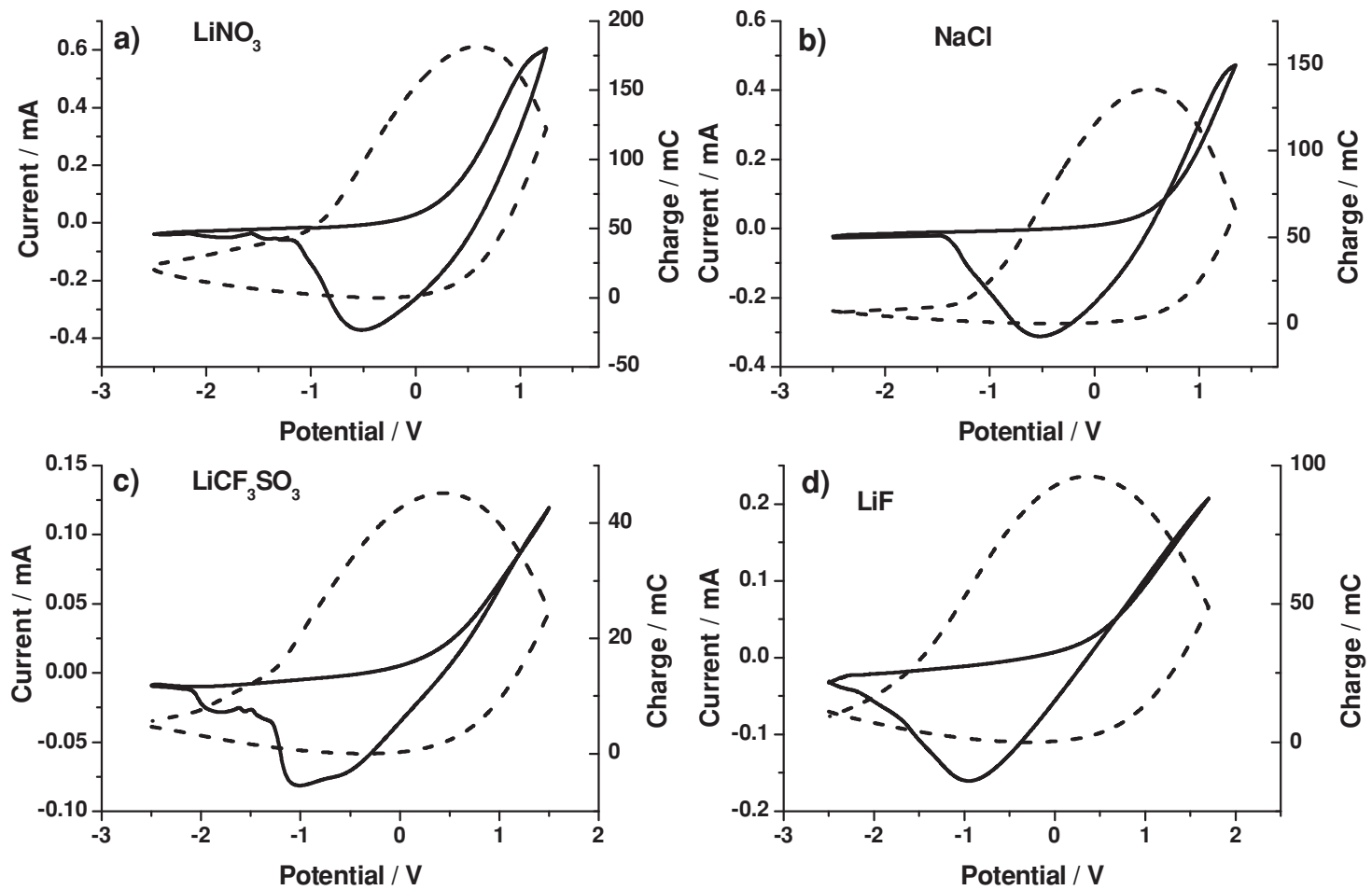

Figure 3. Voltammetric and coulovoltammetric responses of self-supported polypyrrole films in $0.1 \mathrm{M}^{2}$ aqueous solutions of different salts-a) LiNO ${ }_{3}$ b) $\mathrm{NaCl}, \mathrm{c}) \mathrm{LiCF}_{3} \mathrm{SO}_{3}$, d) $\mathrm{LiF}$-at a constant sweep rate of $3 \mathrm{mV} \mathrm{s}^{-1}$

thickness (Figure 4c), corroborating the presence of hydrogen evolution at the metal/polymer interface. As referenced with a clean Pt electrode, the fast hydrogen release starts at $-230 \mathrm{mV}$ (Figure 4d), as deduced from the fast rise of the cathodic current after this potential.

Once again, we can conclude that only coulovoltammetric responses can reveal the presence of irreversible reactions occuring during potential sweeps when the charge involved in those reactions is only a small fraction of the film redox charge.

The voltammetric response also shows a strong packing effect, with the voltammetric loop characteristic of the nucleation-relaxation, when the oxidation starts at the end of the anodic sweep and the beginning of the cathodic sweep.

\subsection{Polypyrrole/Organic Acid Blends}

Protons present in the electrolyte favours, as demonstrated in the previous section, slow discharge on the self-supported polypyrrole electrode. Conducting polymers also allow one to check the influence of protons as constituent parts of the film. Weak organic acids (polymeric or otherwise), or salts of those acids, can be incorporated during electropolymerization to generate polymer blends. ${ }^{[40]}$ Here, we will check if those blends favour proton discharge from aqueous solutions for some of the above-checked neutral electrolytes.

\subsection{Polypyrrole-para Phenolsulfonic Acid (PPy-pPS) Blend}

Figure 5 shows the voltammetric responses in $0.5 \mathrm{M} \mathrm{NaCl}$ aqueous solution (Figure 5a), using as working electrodes: an uncoated platinum electrode (from $-1 \mathrm{~V}$ ), a PPy-pPS-coated platinum electrode (from $-1.2 \mathrm{~V}$ ), or a self-supporting film of PPy-pPS (with a thickness of $100 \mu \mathrm{m}$, a mass of $1.218 \mathrm{mg}$, and a surface area of $9.2 \mathrm{~mm}^{2}$ ) from different cathodic potential limits. Figure $5 \mathrm{~b}$ shows the coulovoltammetric responses from the self-supported film for different cathodic potential limits. At $-1 \mathrm{~V}$, a strong hydrogen release is observed from the clean Pt electrode. This evolution is reproduced from the same potential, but generating lower currents, from the coated Pt electrode. From the self-supported film, the coulovoltammograms present an open structure at more cathodic potentials than $-1.1 \mathrm{~V}$, indicative of the presence of irreversible proton reduction. A very significant shift of the beginning of the polymer oxidation towards a more anodic potential is observed when the self-supported film is cycled (Figure 5a,b) from rising cathodic potential limits, as a result of the most stable energetic structures obtained by deep reduction.

This material in $\mathrm{NaCl}$ aqueous solution is not such a good inhibitor of the cathodic irreversible reactions as polypyrrole (Figures 2 and 3). The exhibited behaviour is close to that of polypyrrole in acid media (Figure 4). Again, if the working electrode has a back Pt metal, a significant increase in the current is observed (Figure 5a), pointing to a proton discharge. The coulovoltammetric responses show the same structural components for the polypyrrole films exchanging small anions.

\subsubsection{Polypyrrole-Dodecylbencensulphonic Acid Blend}

The capacity of the coulovoltammetric responses to reveal structural processes was then checked by using a new polypyrrole material which experiences a prevalent exchange of cations 

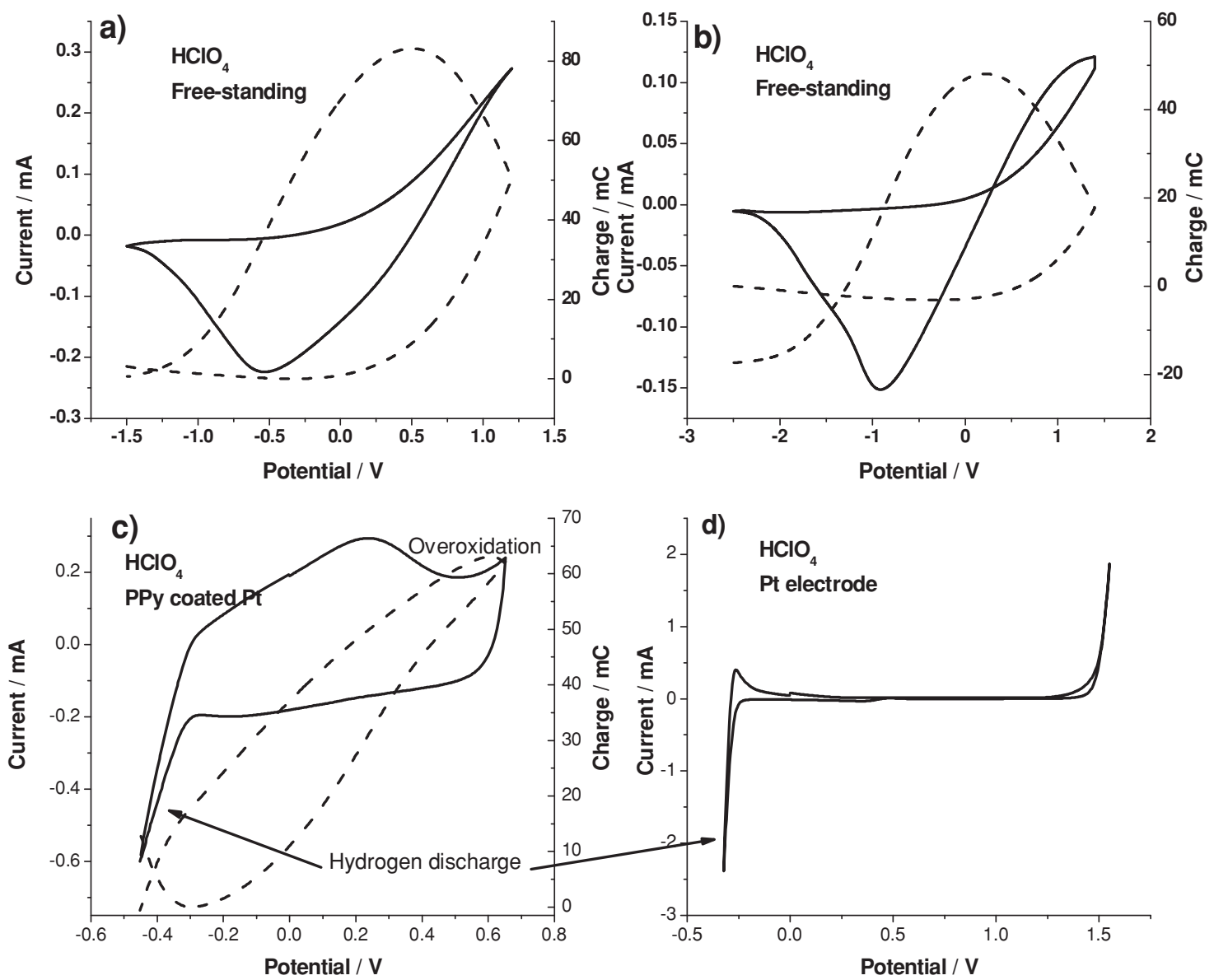

Figure 4. Voltammetric and coulovoltammetric responses of self-supported polypyrrole films in $0.1 \mathrm{M} \mathrm{HClO}_{4}$ aqueous solutions, with a sweep rate of $3 \mathrm{mV} \mathrm{s}^{-1}$, using a) free-standing PPy film from -1.5 to $1.2 \mathrm{~V}$; b) free-standing Ppy film from -2.5 to $1.4 \mathrm{~V}$; c) PPy-coated Pt electrode from - 0.45 to $0.65 \mathrm{~V} ; \mathrm{d}$ ) clean Pt electrode from -0.32 to $1.55 \mathrm{~V}$.
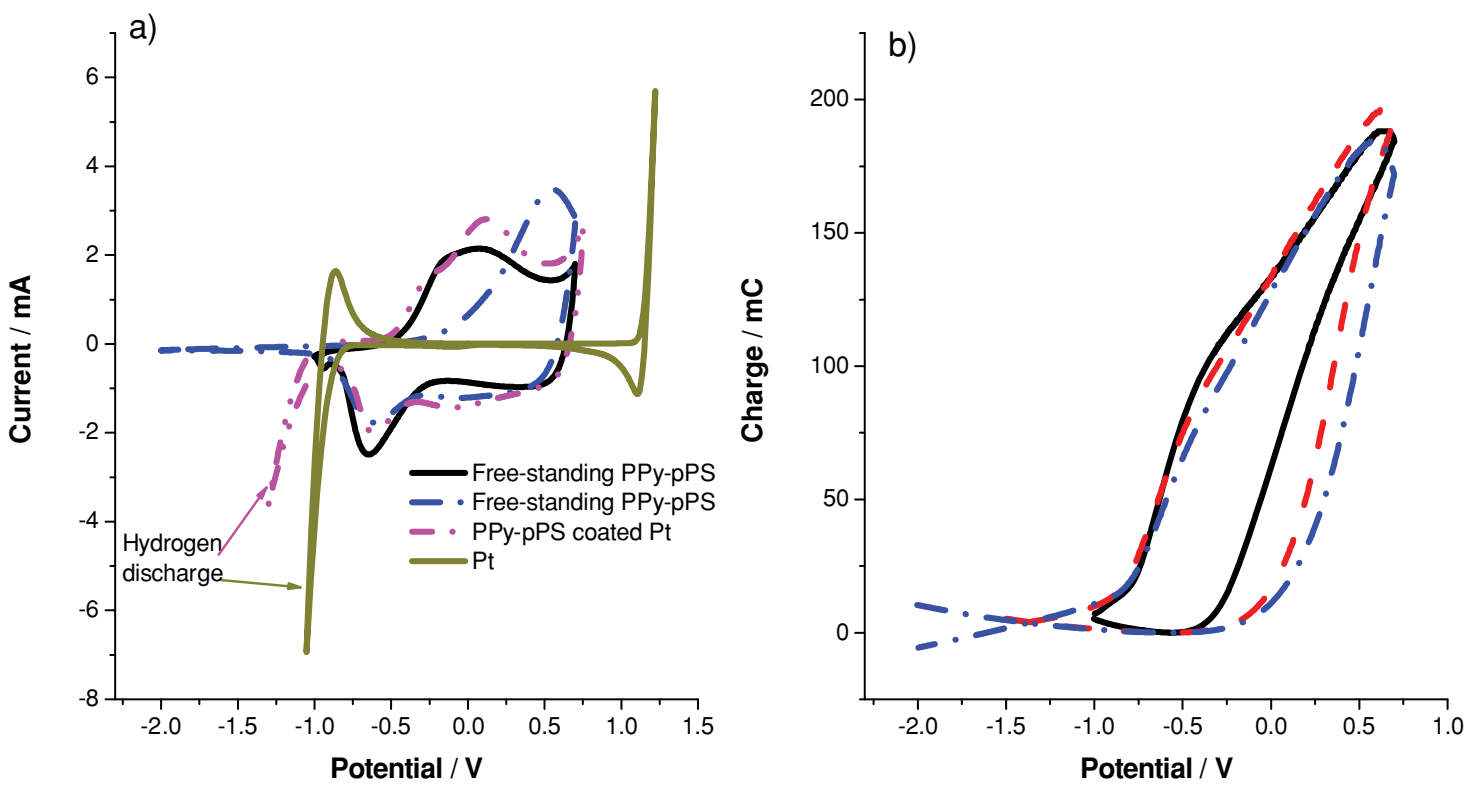

Figure 5. a) Voltammetric responses obtained in $0.5 \mathrm{M} \mathrm{NaCl}$ aqueous solutions from: a clean platinum electrode between $-1 \mathrm{~V}$ and $1.2 \mathrm{~V}$, a polypyrrolepara phenolsulfonic acid (PPy-pPS)-coated platinum foil between $-1.3 \mathrm{~V}$ and $0.75 \mathrm{~V}$, and free-standing PPy-pPS electrodes of the same surface area and thickness between -1 or $-2 \mathrm{~V}$ and $0.75 \mathrm{~V}$. Sweep rate: $10 \mathrm{mV} \mathrm{s}^{-1}$. b) Coulovoltammetric responses obtained from free-standing PPy-pPS films by integration of of the voltammograms from different cathodic limits. 

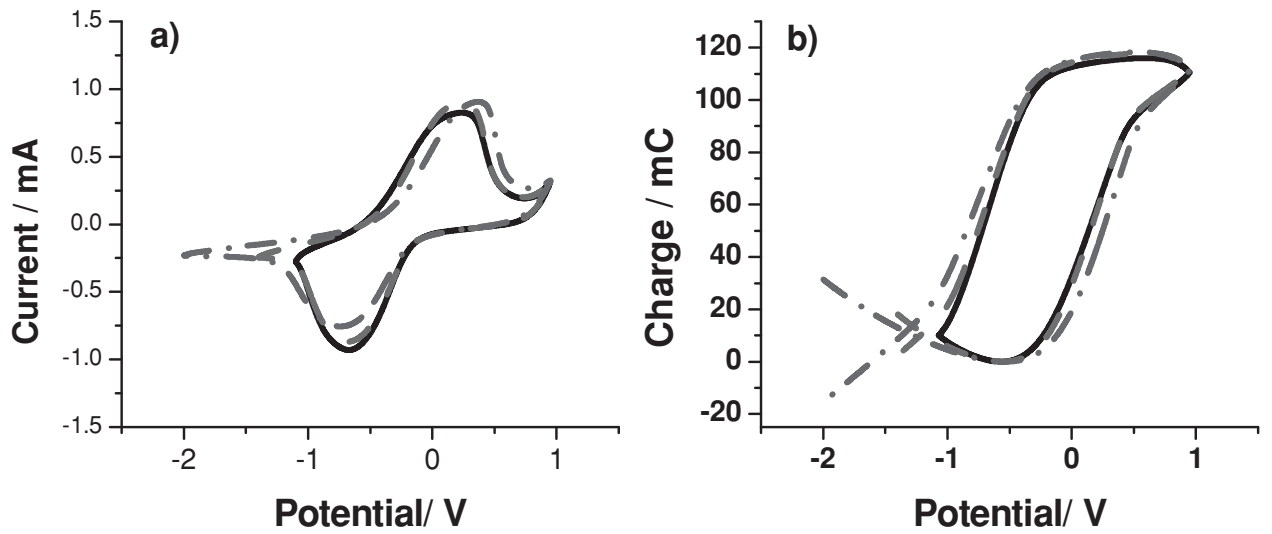

Figure 6. a) Voltammetric and b) coulovoltammetric responses of a polypyrrole-dodecylbencenesulphonic acid (PPy/DBS) blend self-supported polypyrrole film from different cathodic potential limits $(-1,-1.5$, and $-2 \mathrm{~V})$ in $0.1 \mathrm{M}$ aqueous solutions of $\mathrm{LiClO}_{4}$. Sweep rate: $6 \mathrm{mV} \mathrm{s}^{-1}$.

during redox processes: self-supported films of polypyrroledodecylbencensulphonic acid. Due to the exchange of cations for charge balancing, the material shrinks and packs by oxidation with the expulsion of cations, and swells by reduction with the inclusion of balancing cations. The voltammetric and coulovoltammetric responses (Figure 6a and b, respectively) reveal the packing effect of the anodic oxidation by a very slow reduction-relaxation process (very slow evolution of the reduction charge per unit of voltage) from the maximum at the beginning of the reduction process, followed by a fast reduction-swelling process. Up to a cathodic potential limit of $-1.1 \mathrm{~V}$, closed coulovoltammetric responses were obtained. For most cathodic potential limits, the presence of a parallel slow hydrogen evolution is revealed by the open coulovoltammetric response (Figure 7). Again, it is remarkable that the presence of hydrogen release never produces rising cathodic currents

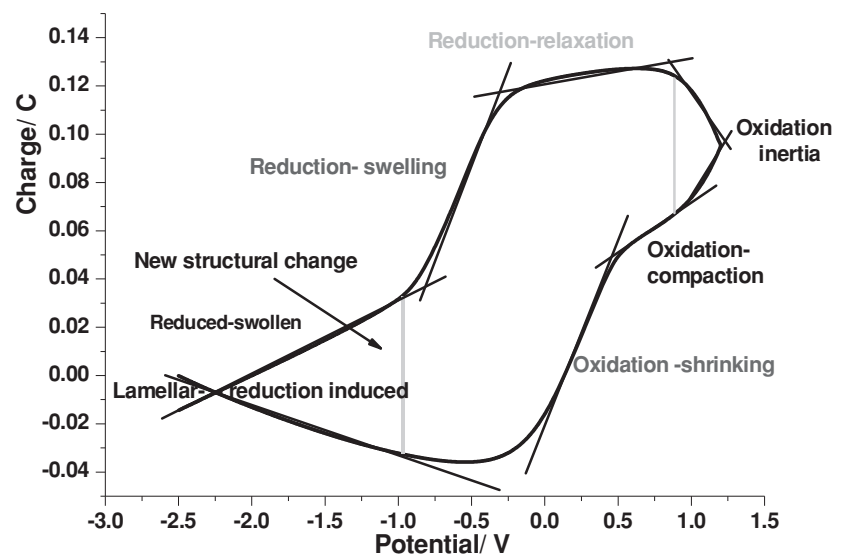

Figure 7. Coulovoltammetric responses from a self-supported PPy/DBS film in $0.1 \mathrm{M} \mathrm{NaCl}$ aqueous solution at $6 \mathrm{mV} \mathrm{s}^{-1}$, showing abrupt slope variations related to abrupt reaction rate changes $\left(\mathrm{dQ} / \mathrm{dE}=1 / \mathrm{Fmd}\left[\mathrm{A}^{-}\right] /\right.$ $\mathrm{dE}$ ) due to the four structural transitions inside the film, driven by the reactions and described by the ESCR model: oxidation-shrinking, oxidation compaction, reduction-relaxation, and reduction-swelling. Moreover, the polymer blend presents a new slow structural variation in the reduced and swollen state that could be due to micellar or lamellar organization of the DBS and water. for increasing cathodic potentials on the voltammograms. How and where this hydrogen evolution takes place remains an open point for future studies.

During the hydrogen release the coulovoltammograms show a new change of the $\mathrm{Q} / \mathrm{V}$ slope. This change announces the presence of a new structural change inside the swollen film including water, DBS, cations, and polypyrrole. This points to the formation of lamellar, micelle-like, or vacuole-like structures inside the material due to the anphyphilic nature of the DBS, as proposed in previous works: ${ }^{[59,60]}$ this new structural aspect and its quantification will require subsequent study.

\section{Discussion}

Self-supported films of conducting polymers exchanging anions during redox processes (p-doping) experience reversible reduction reactions between $-2.5 \mathrm{~V}$ and $0.6 \mathrm{~V}$ in aqueous solution (Figures 2 and 3). They give closed coulovoltammetric responses where the oxidation charge equals the reduction charge: the oxidation-reduction of the film is reversible in the full studied potential range. Inside the studied potential range, a continuous evolution of the charge is observed: the film reaction occurs at any potential.

The film after reduction at $-2.5 \mathrm{~V}$ is re-oxidized during the subsequent anodic potential sweeps, getting steady state voltammetric responses on consecutive potential cycles. This fact contradicts the percolation model, because the reduced film allows the current flow required to reduce and pack the structure, so the reduced film is not an electric insulator. Moreover, the re-oxidation is not initiated at the metal/polymer interface inside the solution, as is also proposed by the percolation model: the metal contact is far away from the solution and direct physical contact between the solution and the metal by possible capillarity along the film was avoided by a transversal paint strip. Taking into account that this hypothesis was inferred by results from the electrochromic front border, ${ }^{[61-69]}$ we will try, in a subsequent paper, a new design of those experiments in order to probe why the oxidation starts at the polymer/solution interface, as proposed by the electrochemically stimulated conformational relaxation (ESCR) model and supported now by the re-oxidation of deep reduced films. 
Both oxidation and reduction coulovoltammetric branches present abrupt slope changes related to reaction rate variations $\left(\mathrm{dQ} / \mathrm{dE}=1 / \mathrm{Fmd}\left[\mathrm{A}^{-}\right] / \mathrm{dE}\right)$, due to structural changes in the film driven by the reactions (reduction-shrinking, reduction-compaction, oxidation-relaxation, and oxidation swelling). The different structural reactive processes are separated by characteristic potentials.

Abrupt slope changes allow a direct and easy graphical determination of the potential ranges, charges, and energies related to each of the structural processes from the slope intersections. Coulovoltammograms constitute a direct, graphical and easy methodology (for both electrochemical specialists and non-specialists) to quantify the reaction-induced structural changes in the films, avoiding the most complex mathematical de-convolution from the theoretical equations of the ESCR model.

Despite the high electro-activity of the film at cathodic potentials, hydrogen evolution from the aqueous solution is inhibited up to higher cathodic potentials than $-2.5 \mathrm{~V}$. Reduced conducting polymers are shown to be the best hydrogen inhibitors among both carbon-based materials such as graphite, graphene, carbon nanotubes, or fullerenes, and metals such as $\mathrm{Hg}$ or $\mathrm{Pb}$. From that point of view, free-standing CP films can compete with graphite, mercury, lead, diamond, or carbon electrodes for some electro-analytical applications in aqueous solutions. ${ }^{[1,52]}$ Only in very strong acid solutions, or in blend films of conducting polymer with organic acids, such as PPy-pPS or PPy/ DBS, a slow discharge of protons can be detected and quantified from the coulovoltammetric responses. The presence of hydrogen release in parallel with the film reduction-compaction at high cathodic potentials is such a slow reaction that, even from strong acid solutions, it doesn't produce any significant increase of the voltammetric cathodic currents. Only open parts of the coulovoltammetric responses reveal its presence.

The experimental results are described and explained by the ESCR model. The oxidized and swollen polymer film shrinks very quickly at the beginning of the voltammetric reduction, under diffusion kinetic control of the counterions through the film towards the solution. When the average distances between chains become similar to the counterion's diameter (anion, solvated or not), the structure closes, still under a partially oxidized state of the film. But conducting polymers are soft materials and the rising reduction over-potentials drive the progressive slow reduction/compaction (low voltammetric cathodic currents) of the film under conformational kinetic control at higher cathodic overpotentials. The reduction becomes slower (reduction-compaction), giving a slower evolution of the coulovoltammetric reduction charge: the structural closing and subsequent reduction-compaction generates a change in the coulovoltammetric slope. The reduction voltammetric maximum is a result of the structural closing by reduction-shrinking: it is the result of a structural response from the film, not a chemical consequence of the film reduction itself.

Over $15 \%$ of the counterions (and positive charges on the chains) remain partially trapped in the film at the closing potential, as deduced from the reduction-compaction charges (Table 1 and Figure 2d). Such a high content variation can be detected by most analytical methodologies and will produce a similar variation in film conductivity and decrease in film volume. In a subsequent manuscript, EDX analysis and parallel determinations of the film conductivities (in inert atmosphere) for rising reduction-compaction states will be used to try to corroborate the decrease of both counterion concentration and electronic conductivity. The proposed expulsion of counterions from the film, driven by the reduction-compaction charge (with the concomitant decrease in film volume by its compaction), will be checked by following the bending movements of PPy/ tape bilayer artificial muscles.

The reduction-compaction process suggests that getting a fully reduced state, without counterions, from thick (several $\mu \mathrm{m})$, free-standing films of CPs is a very difficult task. After the closing potential, rising conformational packed states are obtained, and the expulsion of remaining counterions becomes more and more difficult.

The oxidation under conformational relaxation kinetic control of compacted initial states is initiated, forming nuclei, visualized from electrochromic films, ${ }^{[58,70]}$ predicted by the ESCR model, and here corroborated by the nucleation loops on different voltammetric responses. After coalescence of the relaxed nuclei, the uniform oxidation/swelling of the film goes on under diffusion kinetic control of the counterion inside the film. If the initial state is a partially reduced open gel, uniform oxidation-swelling and a uniform colour change occurs from the beginning of the oxidation reaction.

The coulovoltammetric responses also allow the detection of the different structural processes driven by reactions in films exchanging cations, such as PPy/DBS, that shrink and compact by oxidation, and relax and swell by reduction. One more structural change, not described before from the coulovoltammetric responses, was observed at high cathodic potentials that could be related to the formation of lamellar or micellar structures in the swollen film. This new structural change, now detected from the coulovoltammetric responses, still requires characterization.

Therefore, electrochemical reactions from free-standing films of CPs drive structural changes: conformational movement of the chains and the macroscopic consequences: relaxation, swelling, shrinking, closing, and compaction of the soft gel structure. The coulovoltammetric responses allow the detection of new structural changes taking place in swollen films of CPs exchanging cations and solvent with the electrolyte during reactions.

\section{Conclusions}

The reversible oxidation/reduction of free-standing polypyrrole films in aqueous solutions takes place in the full potential range from $0.65 \mathrm{~V}$ to $-2.5 \mathrm{~V}$, as deduced by the continuous evolution of the consumed charge $\left(\mathrm{dQ}_{\mathrm{red}} / \mathrm{dt}\right)$. The reversibility generates closed-loop coulovoltammetric responses.

The steady state voltammetric responses to consecutive potential cycles in that potential range contradict two of the hypotheses from the percolation model: the insulating nature of the reduced films, and the required metal/polymer contact inside the solution to re-oxidize the film. According to those hypotheses, flat voltammetric responses should be obtained after the first reduction from self-supported films instead of the steady state responses seen. 
Despite the electro-activity of the freestanding film at cathodic potentials, hydrogen evolution from aqueous solutions is inhibited in the full studied potential range from $0.65 \mathrm{~V}$ to 2.5 V. Free-standing CP films can compete, as hydrogen inhibitors, with graphite, mercury, lead, diamond, or carbon electrodes for some electro-analytical applications in aqueous solutions.

The presence of slow hydrogen evolution from acidic solutions or when using blend films, including large organic acids, is revealed by an open part in the coulovoltammetric responses, but cannot be deduced from the voltammetric responses.

Abrupt slope changes on the coulovoltammograms distinguish the presence of four structural reactive processes in the studied potential range: reduction-shrinking, reduction-compaction, oxidation-relaxation, and oxidation-swelling. Potential ranges, charges, and energies related to each of the processes are graphically obtained from the components.

The reduction-compaction process at high cathodic potential consumes over $15 \%$ of the full redox charge of the coulovoltammetric loop.

In films of $\mathrm{CP}$ blends exchanging cations during reactions (swelling by reduction and shrinking by oxidation), coulovoltammetric responses can also be used for the graphical separation and quantification the different structural components of the reactions. From PPy/DBS, a new structural component not described by the ESCR model was observed at high cathodic potential, which can be related to the formation of lamellar or micellar structures inside the swollen reduced film.

\section{Experimental Section}

Pyrrole (Fluka 97\%) was purified by distillation under vacuum using a diaphragm vacuum pump MZ $2 \mathrm{C}$ SCHOTT. Lithium perchlorate ( $\mathrm{LiClO}_{4}$, Aldrich); sodium chloride $(\mathrm{NaCl}$, Panreac); lithium nitrate $\left(\mathrm{LiNO}_{3}, \quad\right.$ Merck); lithium trifluoromethanesulfonate $\left(\mathrm{LiCF}_{3} \mathrm{SO}_{3}\right.$, Aldrich); 4-hydroxybenzenesulfonic acid solution (Aldrich), and; dodecylbenzenesulfonic acid solution (70 wt\% in isopropanol; DBSA; Aldrich) were used as received. Ultrapure water was obtained from Millipore Milli-Q equipment.

All the electrochemical studies were performed using an Autolab electrochemical workstation (PCSTAT-100 potentiostat/galvanostat) connected to a personal computer and controlled through the GPES electrochemical software. The electrogeneration of the polypyrrole films has been described previously. ${ }^{[71,72]}$

PPy-pPS films were prepared at $0{ }^{\circ} \mathrm{C}$ in a one-compartment electrochemical cell using $50 \mathrm{~mL}$ of $0.15 \mathrm{M}$ pyrrole and $0.1 \mathrm{M}$ pPS (4-hydroxybenzenesulfonic acid) aqueous solution. Temperatures were controlled by using a Julabo T25 cryostat/thermostat having a precision of $0.1{ }^{\circ} \mathrm{C}$. As working electrodes were used an AISI316 stainless steel plate (with a thickness of $1.24 \mathrm{~mm}$ and with a surface area of $25 \times 15 \mathrm{~mm}$ ) or a Ti plate having similar dimensions. The electropolymerization was performed on both sides of the immersed electrode fraction, having an area of $20 \times 15 \mathrm{~mm}$ on each side. Two stainless steel counterelectrodes having an area of $25 \times 15 \mathrm{~mm}$ were located symmetrically and parallel, at $1 \mathrm{~cm}$, on both sides of the stainless steel working electrode to obtain a uniform electric field. A standard $\mathrm{Ag} / \mathrm{AgCl}(3 \mathrm{M} \mathrm{KCl})$ electrode from Metrohm was used as the reference electrode. The PPy-pPS film was electrogenerated by applying a constant anodic current density of $0.5 \mathrm{~mA} \mathrm{~cm}^{-2}$ for $7200 \mathrm{~s}$ through the working electrode consuming 4.8 $\mathrm{C}$ of charge. The potential of the working electrodes remains almost constant, around $0.65 \mathrm{mV}$, during the film electrogeneration. Once coated, the polypyrrole film coating the working electrode borders were scraped. The PPy-pPS films once peeled off from the working electrode, were rinsed with water, dried in air at room temperature and cut as strips having all of them the same dimensions.

Films of polypyrrole films doped with dodecylbenzenesulfonate (PPy-DBS blends) were prepared at room temperature $\left(24 \pm 2^{\circ} \mathrm{C}\right)$ in dark conditions using a one-compartment electrochemical cell from $0.2 \mathrm{M}$ DBSA and $0.2 \mathrm{M}$ pyrrole aqueous solutions. AISI 316 stainless steel plates were used as the working electrode. As counter electrodes two larger electrodes $\left(10 \mathrm{~cm}^{2}\right)$ of the same material were used placed symmetrically on both sides of the working electrode in order to obtain a uniform electrical field. $\mathrm{An} \mathrm{Ag} / \mathrm{AgCl}(3 \mathrm{M} \mathrm{KCl})$ from Metrohm was used as the reference electrode. All the potentials in this work are referred to it. On this two uniform PPy-DBS films, one by side of the working electrode, were obtained. They were electrogenerated by applying a constant anodic current of $2 \mathrm{~mA} \mathrm{~cm}$ over $2 \mathrm{~h}$. Then the working electrode was submerged in ultrapure water for $24 \mathrm{~h}$ in order to remove the DBSA molecules adsorbed on the polymer surface. Two different reduced films were peeled off, one by every steel electrode side, with a mass of $30 \pm 0.2 \mathrm{mg}$ per film and a thickness of $50 \pm 10 \mu \mathrm{m}$.

The mass of the dry and reduced polymer films was determined by means of a precision ultramicrobalance Sartorious SC2 $( \pm 0.1 \mu \mathrm{g})$. Film thicknesses were measured using a COMECTA electronic digital micrometer with a precision of $\pm 1 \mu \mathrm{m}$.

\section{Acknowledgements}

The authors acknowledge financial support from the Spanish Government, Projects MAT2011-24973, MAT2008-06702, from the Seneca Foundation, the Mexican Government and the Universidad Autónoma del Estado de México. J.G. Martinez acknowledges Spanish Education Ministry for a FPU grant (AP2010-3460).

Received: July 23, 2013

Revised: September 13, 2013 Published online: October 31, 2013

[1] T. F. Otero, M. Alfaro, V. Martinez, M. A. Perez, J. G. Martinez, Adv. Funct. Mater. 2013, 23, 3929

[2] T. F. Otero, J. G. Martinez, J. Mater. Chem. B 2012, 1, 26

[3] T. F. Otero, H. Grande, J. Rodríguez, J. Electroanal. Chem. 1995, 394, 211.

[4] T. F. Otero, H. Grande, J. Electroanal. Chem. 1996, 414, 171.

[5] T. F. Otero, H. Grande, J. Rodríguez, Electrochim. Acta 1996, 41, 1863.

[6] T. F. Otero, H. Grande, J. Rodriguez, Synthetic Met. 1996, 76, 285.

[7] T. F. Otero, H. Grande, J. Rodriguez, Synthetic Met. 1996, 83, 205.

[8] T. F. Otero, H. Grande, J. Rodriguez, J. Phys. Org. Chem. 1996, 9, 381.

[9] T. F. Otero, H.-J. Grande, J. Rodríguez, J. Phys. Chem. B 1997, 101, 3688.

[10] T. F. Otero, H. Grande, J. Rodríguez, J. Phys. Chem. B 1997, 101, 8525.

[11] T. F. Otero, H. Grande, J. Rodriguez, Synth. Met. 1997, 85, 1077.

[12] T. F. Otero, H. J. Grande, Colloid Surf. A-Physicochem. Eng. Asp. 1998, 134, 85

[13] H. Grande, T. F. Otero, I. Cantero, J. Non-Cryst. Solids 1998, 235 237, 619.

[14] E. Volpi, M. Trueba, S. P. Trasatti, Prog. Org. Coat. 2012, 74, 376

[15] M. Rizzi, M. Trueba, S. P. Trasatti, Synthetic Met. 2011, 161, 23.

[16] T. F. Otero, J. G. Martinez, Adv. Funct. Mater. 2013, 23, 404.

[17] A. Zykwinska, W. Domagala, A. Czardybon, B. Pilawa, M. Lapkowski, Chem. Phys. 2003, 292, 31. 
[18] J. Heinze, B. A. Frontana-Uribe, S. Ludwigs, Chem. Rev. 2010, 110, 4724.

[19] K. Aoki, M. Kawase, J. Electroanal. Chem. 1994, 377, 125.

[20] J. Q. Li, K. Aoki, J. Electroanal. Chem. 1998, 453, 107.

[21] J. Fournier, G. Boiteux, G. Seytre, G. Marichy, Synthetic Met. 1997, $84,839$.

[22] L. Vandyke, S. Kuwabata, C. Martin, J. Electrochem. Soc. 1993, 140, 2754.

[23] A. J. Heeger, Synthetic Met. 2001, 125, 23.

[24] J. Heinze, P. Tschuncky, A. Smie, J. Solid State Electroch. 1998, 2, 102.

[25] D. P. Almond, C. R. Bowen, D. a. S. Rees, J. Phys. D-Appl. Phys. 2006, 39, 1295.

[26] G. Ambrosetti, N. Johner, C. Grimaldi, T. Maeder, P. Ryser, A. Danani, J. Appl. Phys. 2009, 106, 016103.

[27] M. Heaney, Phys. Rev. B 1995, 52, 12477.

[28] M. E. Mezeme, S. El Bouazzaoui, M. E. Achour, C. Brosseau, J. Appl. Phys. 2011, 109, 074107.

[29] B. Mu, P. Liu, X. Yu, F. Pan, Z. Gao, X. Liu, Synthetic Met. 2010, 160, 2329.

[30] H. Naarmann, N. Theophilou, Synthetic Met. 1987, 22, 1.

[31] J. Obrzut, J. F. Douglas, S. B. Kharchenko, K. B. Migler, Phys. Rev. B 2007, 76, 195420.

[32] D. Ofer, R. M. Crooks, M. S. Wrighton, J. Am. Chem. Soc. 1990, 112, 7869.

[33] V. Panwar, R. M. Mehra, Polym. Eng. Sci. 2008, 48, 2178.

[34] J. Y. Yi, G. M. Choi, J. Electroceram. 1999, 3, 361.

[35] G. Zotti, R. Salmaso, M. C. Gallazzi, R. A. Marin, Chem. Mat. 1997, 9, 791.

[36] C. C. B. Bufon, J. Vollmer, T. Heinzel, P. Espindola, H. John, J. Heinze, J. Phys. Chem. B 2005, 109, 19191.

[37] B. J. S. Jones, M. Kalaji, Electrochim. Acta 2005, 50, 4505.

[38] J. C. Lacroix, K. Fraoua, P. C. Lacaze, J. Electroanal. Chem. 1998, 444, 83.

[39] T. F. Otero, J. G. Martinez, J. Arias-Pardilla, Electrochim. Acta 2012, 84, 112.

[40] T. F. Otero, Polym. Rev. 2013, 53, 311.

[41] K. Aoki, J. Electroanal. Chem. 1991, 310, 1.

[42] G. Inzelt, Electrochim. Acta 1989, 34, 83.

[43] M. Kalaji, L. M. Peter, L. M. Abrantes, J. C. Mesquita, J. Electroanal. Chem. 1989, 274, 289.

[44] M. Kalaji, L. Nyholm, L. Peter, J. Electroanal. Chem. 1992, 325, 269.

[45] C. Odin, M. Nechtschein, Phys. Rev. Lett. 1991, 67, 1114.

[46] C. Odin, M. Nechtschein, P. Hapiot, Synthetic Met. 1992, 47, 329.

[47] B. Villeret, M. Nechtschein, Phys. Rev. Lett. 1989, 63, 1285.
[48] M. A. Vorotyntsev, E. Vieil, J. Heinze, J. Electroanal. Chem. 1998, $450,121$.

[49] L. Valero, J. Arias-Pardilla, M. Smit, J. Cauich-Rodríguez, T. F. Otero, Polym. Int. 2010, 59, 337.

[50] T. F. Otero, M. Caballero Romero, Polym. Int. 2010, 59, 329.

[51] D. L. Dreyfus, Diamond for Electronic Applications, Materials Research Society Symposium Proceedings v. 416, Materials Research Society, Pittsburgh, Pa. 1996

[52] H. B. Martin, A. Argoitia, U. Landau, A. B. Anderson, J. C. Angus, J. Electrochem. Soc. 1996, 143, L133.

[53] R. Imhof, P. Novak, J. Electrochem. Soc. 1998, 145, 1081.

[54] J. G. Martinez, T. Sugino, K. Asaka, T. F. Otero, ChemPhysChem 2012, 13, 2108.

[55] A. Petr, L. Dunsch, J. Phys. Chem. 1996, 100, 4867.

[56] A. Osterholm, A. Petr, C. Kvarnstroem, A. Ivaska, L. Dunsch, J. Phys. Chem. B 2008, 112, 14149.

[57] A. Osterholm, B. Meana-Esteban, C. Kvarnstrom, A. Ivaska, J. Phys. Chem. B 2008, 112, 6331.

[58] T. F. Otero, I. Boyano, ChemPhysChem 2003, 4, 868.

[59] B. J. West, T. F. Otero, B. Shapiro, E. Smela, J. Phys. Chem. B 2009, 113,1277

[60] W. Wernet, M. Monkenbusch, G. Wegner, Mol. Cryst. Liq. Cryst. 1985, 118, 193.

[61] Y. Tezuka, K. Aoki, J. Electroanal. Chem. 1989, 273, 161.

[62] Y. Tezuka, S. Ohyama, T. Ishii, K. Aoki, Bull. Chem. Soc. Jpn. 1991, 64, 2045.

[63] Y. Tezuka, T. Kimura, T. Ishii, K. Aoki, J. Electroanal. Chem. 1995, 395, 51.

[64] Y. Tezuka, T. Ishii, K. Aoki, J. Electroanal. Chem. 1996, 402, 161.

[65] X. Z. Wang, B. Shapiro, E. Smela, Adv. Mater. 2004, 16, 1605.

[66] X. Z. Wang, E. Smela, In Smart Structures and Materials 2005: Electroactive Polymer Actuators and Devices(EAPAD) (Ed: Y. B. Cohen), SPIE-Int Soc Optical Engineering, Bellingham 2005, Vol. 5759, pp.414-422.

[67] X. Wang, E. Smela, In Smart Structures and Materials 2006: Electroactive Polymer Actuators and Devices (EAPAD) (Ed: Y. B. Cohen), SPIE-Int Soc Optical Engineering, Bellingham 2006, Vol. 6168, pp.W1680-W1680.

[68] X. Wang, E. Smela, J. Phys. Chem. C 2009, 113, 359.

[69] X. Wang, E. Smela, J. Phys. Chem. C 2009, 113, 369

[70] H. Randriamahazaka, T. Bonnotte, V. Noel, P. Martin, J. Ghilane, K. Asaka, J.-C. Lacroix, J. Phys. Chem. B 2011, 115, 205.

[71] T. F. Otero, J. J. Sanchez, J. G. Martinez, J. Phys. Chem. B 2012, 116, 5279.

[72] J. G. Martinez, T. F. Otero, J. Phys. Chem. B 2012, 116, 9223. 